OPEN ACCESS

Edited by:

Theresa Kwong,

Hong Kong Baptist University,

Hong Kong

Reviewed by:

Lisa Ying Ngor LAW, Hong Kong Baptist University,

Hong Kong

Ricky Lam

Hong Kong Baptist University, Hong Kong

*Correspondence:

Dave E. Marcial

demarcia/@su.edu.ph

Specialty section:

This article was submitted to Digital Learning Innovations,

a section of the journal

Frontiers in Education

Received: 30 November 2020 Accepted: 03 March 2021 Published: 30 March 2021

Citation:

Marcial DE, dela Peña L, Montemayor J and Dy J (2021) The Design of a Gamified Responsible Use of Social Media.

Front. Educ. 6:635278. doi: 10.3389/feduc.2021.635278

\section{The Design of a Gamified Responsible Use of Social Media}

\author{
Dave E. Marcial ${ }^{1 *}$, Lawrence dela Peña ${ }^{2}$, Jade Montemayor ${ }^{1}$ and Joy Dy ${ }^{3}$ \\ ${ }^{1}$ Silliman Online University Learning, Silliman University, Dumaguete, Philippines, ${ }^{2}$ Technology Business Incubation Office, \\ Silliman University, Dumaguete, Philippines, ${ }^{3}$ College of Computer Studies, Silliman University, Dumaguete, Philippines
}

Social media is part of almost everyone's daily life. Its networking facilities redefines the way people connect and interact with each other. However, social media is reported being misused in different ways, especially the millennials. There is a need to elevate the teens' level of empowerment on the responsible use of social media. Other technological innovations like augmented reality (AR) and digital gamification provides pedagogical benefits. Digital gamification in the classroom is a teaching strategy that translates content and delivery into a game using digital technology. On the other hand, AR is an emerging technology to enlarge real-life situations in multimedia. Research shows both technologies increase interactivity well as attention span among the learners. Additionally, these technologies, including social media, are among the many useful tools in teaching twenty first century learners once correctly used. With this, a game-based mobile application was developed to advocate responsible use of social media among teens. The learning content was gamified in augmented reality to provide an innovative teaching and learning way at Silliman University. This paper describes the gamification design of the learning trail on the topic of responsible use of social media. Specifically, it presents the publishing process of the augmented reality mobile application about responsible use of social media. Kuhlmann's 3C Model (Challenge, Choices, Consequences) was utilized to formulate the learning content. It also demonstrates the design phases, game mechanics, and the general evaluation of the learning application. Four challenges were developed. These are (a) be familiar with security and privacy policies, (b) do not express concerns about others, even if you think you are anonymous, (c) respond to digital offenders, (d) do not tell the world about an upcoming vacation. These challenges were translated into graphics and animations. The animated material was compiled, programmed, and published to a server of the mobile application. The gamified learning trail on responsible use of social media is accessible through QR codes leading to the augmented reality interface. The design was validated and found to be relevant and engaging.

Keywords: gamification, ICT in education, whole-person education, augmented realitiy, e-learning

\section{INTRODUCTION AND LITERATURE REVIEW}

Technological advancement is rapidly increasing, which affects humanity. It affects how people think and interact and how people live and decide. Among the emerging of today's technological innovations that redefine online activities is social media. Social media usage is rising. An $\sim 3.6$ billion people were using social media globally in 2020 and are projected to 
rise to almost 4.41 billion in 2025 (Clement, 2020). Likewise, the GlobalWebIndex's flagship report on social media in 2019 stated that $98 \%$ of consumers had used a social media network in the past month; being an internet user means being a social media user (GlobalWebIndex., 2019). It also reported that $63 \%$ of people feel most comfortable sharing and talking about messaging apps. It also reported that $60 \%$ of internet users said they had watched a video on Facebook, Twitter, Snapchat, or Instagram in the past month.

Interestingly, the Philippines ranked first in terms of user engagement. An average time per day spent is $4 \mathrm{~h}$ and $1 \mathrm{~min}$, twice the amount of time spent by U.S. users (Clement, 2020). These global reports illustrate how social media changes how people communicate and how information is shared. It can also be asserted how people, especially the Filipinos on how engaged they are and how they use social media. Webster's dictionary defines social media as "forms of electronic communication through which users create online communities to share information, ideas, personal messages, and other content."

Studies have shown the pedagogical benefits of social media in learning and education. Social media applications "support the acquisition, access, manipulation, processing, retrieval, presentation, and visualization of information within a teaching/learning space [White et al., 2014].” Sheldon (2015) summarized the benefits of social media education surrounding student-centeredness, interactivity, customization, collaboration, access, engagement, creativity, and support system, among others. Social media applications encompass wikis, blogs, microblogs, online groups, forums, podcasts, video-sharing, web mashups, virtual worlds, community sharing, social repositories, social tagging, bookmarking, and many more.

Gamification is defined as "the process of adding games or game-like elements to something so as to encourage participation" [Merriam-Webster. (n.d).]. "Gamification is using game-based mechanics, aesthetics, and game-thinking to engage people, motivate action, promote learning, and solve problems" (Kapp et al., 2013). Fuchs et al. (2014) rethinks gamification as the "permeation of economic, political, and social contexts by game-elements such as awards, rule structures, and interfaces that are inspired by video games." Gamification involves three general principles: mechanics, dynamics, and emotions (Robson et al., 2015). Further, gamification is a teaching strategy that generally translates content and delivery into a game in the form of "points, badges, and leaderboards as incentives and motivations to be productive" (Fuchs et al., 2014). There are two general types of gamification in education. These are structural and content gamification with the primary intention to achieve learning outcomes through content, stimulate action, influence behavior, and drive innovation (Kapp et al., 2013). Among the popular frameworks in assessing gamification's effectiveness in teaching and learning includes the Kapp Framework, Csikszentmihalyi's Flow Framework, and Student Intrinsic Motivation for Persistence in Learning Environments Matrix (Bell, 2018). Studies show that gamified content are more lifelike when applied with augmented reality.
Augmented reality (AR) is defined as "a wide spectrum of technologies that project computer-generated materials, such as text, images, and video, onto users' perceptions of the real world" (Chi-Yin Yuen et al., 2011). It is depicted as "enhancement of the real world by computer-generated content which is tied to specific locations or activities" (Krämer, 2017). Wu et al. (2013) asserts that instructional approaches in AR must emphasize the roles, tasks, and locations. Forms of AR include markerbased, markerless, projection-based, and superimposition-based [Profiletree.com. (a)., 2020], which generally comprises displays, input devices, tracking, and computers (Carmigniani and Furht, 2011). Augmented reality in the classroom is usually coupled with mobile technology because it is low cost and easy to integrate appropriate to the course and education type. Gu and Duh (2011) concluded that mobile-based AR in education must emphasize performance, portability, and extendibility. Among the most common technology in augmented reality application is QR (Quick Response) code.

This paper describes the gamification design of a learning trail on the topic of responsible use of social media. Specifically, it presents the publishing process of the augmented reality mobile application about responsible use of social media.

\section{BACKGROUND OF THE PROJECT}

\section{The Project}

The project is about gamifying teaching delivery about the topic "responsible use of social media." The game is mobile-based that runs in both iOS and Android operating systems. It is a learning trail. The project is one of the research's deliverables, "Integrating Augmented Reality and Gamification in Silliman: An International Partnership to Improve Student's 21st-Century Skills." The research is funded by the United Board for Christian Higher Education, a non-governmental organization that is "committed to education that develops the whole personintellectually, spiritually, and ethically." The project is also in partnership with the Centre for Holistic Teaching and Learning, Hong Kong Baptist University.

\section{The Learning Goal and Outcomes}

The game is an innovative integration of maximizing digital technology into teaching instruction in a fun, enjoyable, exciting, and entertaining way among the students at Silliman University. It comes into two-interrelated general goals. First, it aims to educate students about responsible use of social media. Specifically, the game allows students to think critically and decide the best action of becoming a responsible social media user. Likewise, the game presented a checklist of dos and don'ts in social media utilization. The game's second goal is to orient students, especially the freshmen, about the university library system. Specifically, the game offers showcase four (4) locations and services in the library. At the end of the game, players are expected to understand better becoming responsible digital netizens. Likewise, players are also expected to familiarize some of the library services of the University. 


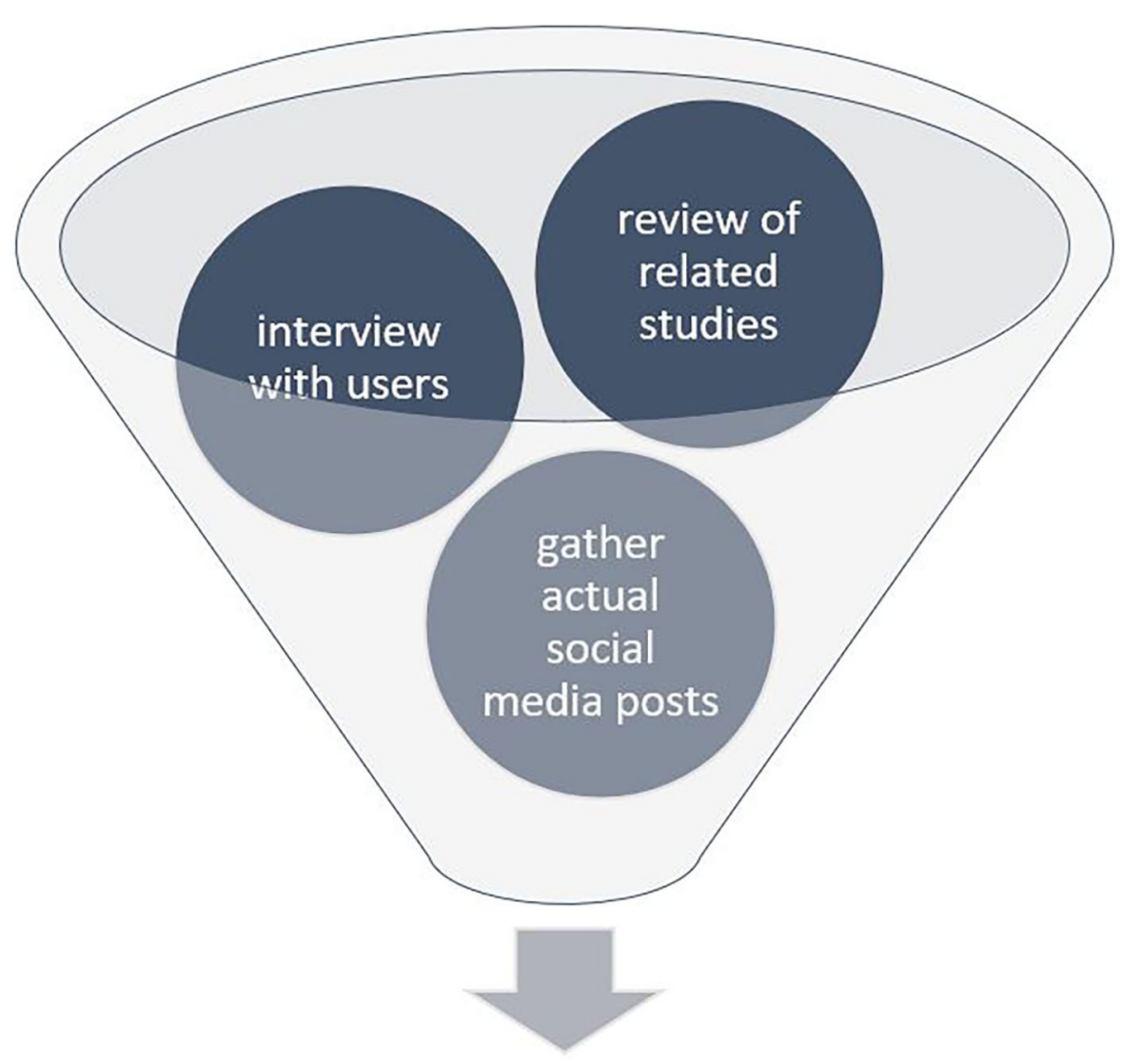

scenarios

FIGURE 1 | Scenario Analysis.

\section{Why "Responsible Use of Social Media?"}

While social media provides vast educational opportunities, technology is among the many risk sources to everyone, especially the millennials. Studies show that teenagers are more engaged in social media. In a Statistica survey of 1317 years old, $16 \%$ of teens admitted checking their social feeds nearly constantly. Another $27 \%$ do so on an hourly basis (Richter, 2018).

"Young digital citizens in the Asia Pacific region experienced a multitude of risks posed by ICT such as cyberbullying, fake news, spamming, internet or technology addiction, health and wellness issues, identity theft, fraud and scams, pornography, and online sex trafficking." (UNESCO, 2018) In a survey of about 1,500 young people ages 16-24 [Royal Society for Public Health. (n.d)., 2019], 91\% of 16-24-year-olds use the internet for social networking, 7 out of 10 young people report experiencing cyber-bullying through social media, $37 \%$ of young people report being cyber-bullied on a high-frequency basis, young people are twice as likely to be bullied on Facebook than on any other social network. Approximately $5 \%$ of young people around the world suffer from social media addiction. In another survey among 1,000 kids age 13-17 in 2018 (Common Sense
Media., 2018), 57\% of all teens agree that using social media often distracts them when they should be doing homework. The study also revealed that teens do not value face-to-face communication with friends as much as they used to do. Further, some of the destructive effects of social media on children and teenagers include hate speech, social distrust, cyberbullying, identity theft, cyber-stalking, explicit or violent imagery, sharing too much, online grooming, emotional implications, and lack of interpersonal skills (Techno Crazed., 2014).

The \#StatusofMind report by RSPH and the Young Health Movement (YHM) listed the 14 health and well-being-related issues of social media. These are awareness and understanding of other people's health experiences, access to expert health information you know you can trust, emotional support, anxiety, depression, loneliness, sleep, self-expression, self-identity, body image, real-world relationships, community building, bullying, and FOMO (Fear of Missing Out) [Royal Society for Public Health. (n.d)., 2019].

There is a need to give attention to this emerging issue among the youth. Likewise, every educator's job is to guide and educate the youth about the risk of too much engagement with social media. There is a need to deepen our advocacy on digital 


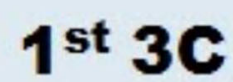

Learner gets to consequence \& then proceeds to a new challenge.

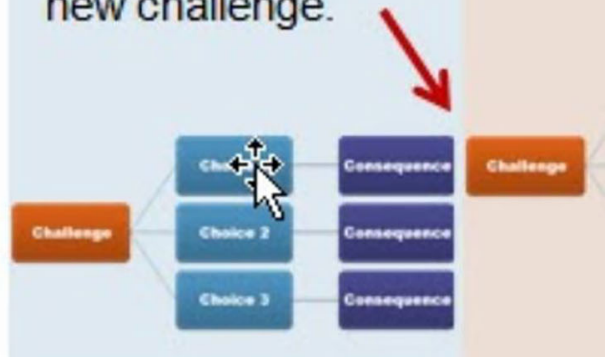

\section{$2^{\text {nd }}$ 3C}

\section{$3^{\text {rd }} \mathbf{3 C}$}

\section{Consequence is a new challenge.}
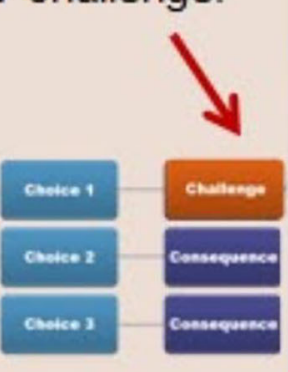

Could

continue forever.

FIGURE 2 | Kuhlmann's 3C Model (Challenge, Choices, Consequences).

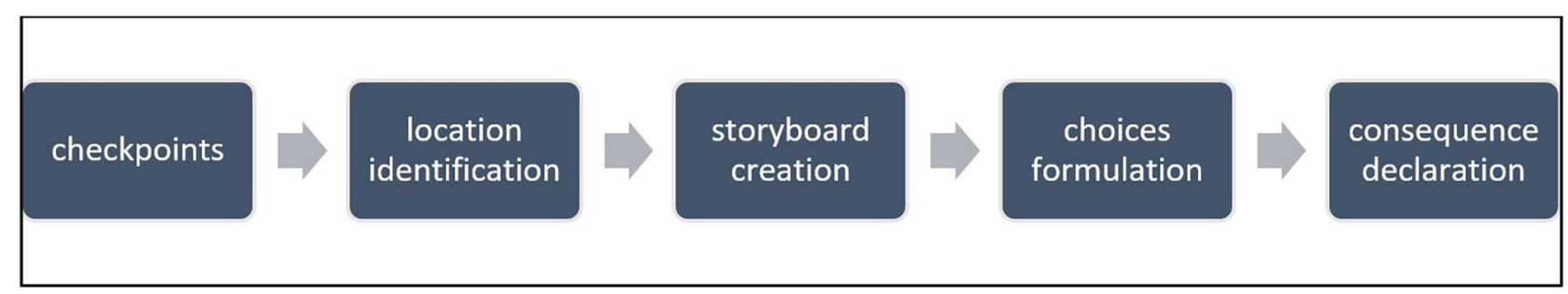

FIGURE 3 | Designing Challenges, Choices, and Consequences.

citizenship and social media's responsible use before these youth will be obsessed. Their health and well-being will be affected.

\section{THE INSTRUCTIONAL DESIGN}

The topic "responsible use of social media" discusses the subjects Empowerment Technologies in senior high school, Computer Ethics, and other degree-based computer fundamental courses at tertiary level. A micro-learning approach was utilized in designing the learning content, which emphasizes precise tips in becoming a responsible user of social media.

The ADDIE model was utilized in the conduct of the overall instructional design. These processes include: Analysis, Design, Develop, Implement, and Evaluate.

\section{The Analysis Phase}

During the analysis phase, the team is guided with the principles of the Forrester Problem Analysis Method-problem definition, evidence, impacts, causes, and recommendations (Gonsenhauser, 2017). Specifically, an intensive review of related studies was conducted about digital citizenship, netiquette, and responsible use of social media. Ten 18-years old students were interviewed about their knowledge, attitude, and practices toward social media. The team also checked several online groups, online forums, and online fan pages on Facebook, Twitter, and other independent blogs. The team checked on the actual postings that are perceived as fake, unwanted, offensive, and unbecoming. News and other press releases in local and foreign periodicals about the reckless use of social media were also reviewed. For example, posted on PhilStar.com, "NBI summons Mocha for fake news" (Cayabyab, 2020). This process is illustrated in Figure 1.

\section{The Design Phase}

Scenarios, also known as checkpoints, were identified. Each checkpoint consisted of a situation, options to select, and aftereffect, based on Kuhlmann's 3C Model (Challenge, Choices, Consequences), shown in Figure 2. The 3C model is an interactive scenario-building where "each scenario consists of a challenge, some choices, and then consequences of those choices" (Kuhlmann, 2009). It aims to challenge the learner's understanding or assumptions. The model shows choices for the learner's decision making. In every decision made, a consequence is provided for feedbacking and guidance. 
TABLE 1 | Scenario 1.

\begin{tabular}{ll}
\hline Checkpoint 1 & Be familiar with security and privacy policies \\
\hline
\end{tabular}

Location

Challenge
Ground floor, Entrance, Main Library

Max meets Marah at the main entrance of the main library. Marah told Max to create a Facebook account as one of the requirements in the Social Networking Class. So, Max created an account. If you were Marah, what advice would you give to Max being a first-time user of Facebook?

\section{Choices}

1. Be selective with friend requests. If you do not know the account or the person, do not accept their request. It could be a fake account. Likewise, do not add to your network your parents too. They will monitor you.

2. Set up your security answers. Use the default password given by the school personnel.

3. For easy recognition, reveal your information like residential address, financial details, phone number. The more details and information you post, the easier it is to have your identity known.

4. Become familiar and conversant with the privacy policies of the social media channels you use and customize your privacy settings to control who sees what.

\section{Consequences}

1. Being selective to friends' requests is one of the responsible uses of social media. Do not add fake accounts. You should be aware that what you posted will stay forever. Do not post anything that you do not want your future employers to see something negative. However, do not block your parents. Research suggests that parents should follow their children online. This ensures oversight in case there are an issue and a "check and balance" of content.

2. No! Always use a strong password. The longer it is with a combination of numbers, letters, and special characters, the more secure it will be. Passwords must be unique and must be different from your other social media accounts. An additional measure is to password protect your device.

3. Be extra careful about what you posted and share. Do not reveal sensitive personal information such as a home address, bank account details, phone number. The more details and information you post, the easier it is to have your identity stolen and taken.

4. This is excellent advice! Read thoroughly the privacy policies of the social media channels you use and customize your privacy settings to control who sees what. Be selective to friend's requests, but do not block your parents, siblings, and family members. Be accountable. Always remember that there is no such instance or thing as $100 \%$ private online. Use social media meaningfully to showcase your aptitude.

TABLE 2 | Scenario 2.

Checkpoint 2

Location
Challenge

Do not express concerns about others, even if you think you are anonymous

\section{2nd Floor, CyberLibrary, Main Library}

Max is browsing his new Facebook account. He saw a public post of his best friend Giorjoe, a freshman student, complaining about their class's particular requirement, and vented frustrations about the teacher's favoritism. Max remembered that he felt the same feelings when he was enrolled during the said teacher last year. Max failed in this class too. If you were Max, what should you do to help Giorjoe immediately?

Choices Consequences

1. Chat with Giorjoe privately and ask him for a meet-up to discuss the matter.

1. You are a responsible social media user. Use social media as a means to interconnect and communicate effectively and efficiently. Social media is not a platform to complain, protest, criticize, or vent your frustrations. Be a source of useful and relevant information. Do not gossip! Always remember to THINK about what you are going to post. T-is it Truthful, $\mathrm{H}-$ does it Help? I-does it Inspire? $\mathrm{N}$ - is it Nice or Necessary? $\mathrm{K}$ - is it Kind?

2. That is not a responsible method of using social media. Do not use social media to complain, protest, or criticize. Do not use social media platforms to vent your frustrations. Do not use social media to express your concerns about others, even if you think you are anonymous. Always remember to THINK about what you are going to post. T-is it Truthful, $\mathrm{H}-$ does it Help? I-does it Inspire? N-is it Nice or Necessary? K-is it Kind?

3. That is not a responsible technique of using social media. Be wary of oversharing; remember that digital footprints stay forever. Be a source of useful and relevant information. Your friends and networks do not need to know every emotion you or your special friends have. For sure, you do not want to be an accessory to any crime. Ask yourself about these questions before sharing: Is the post TRUE or a rumor? Is the post HELPFUL or harmful? Is the post NEEDED or irrelevant?

4. That is not a responsible mode of using social media. While it is true that group chat is a great way to engage with your friends on a personal and intimate level, you should ask yourself as the creator of the group: Is the post HELPFUL or harmful? Is the post INFORMATIONAL or gossip? Is the post KIND or harsh? As the saying by Frank Clark: "Gossip need not be false to be evil-there is a lot of truth that should not be passed around."
In the responsible use of social media AR Trail, challenges are presented into a set of questions for the players to learn about a particular situation, dilemma, or problem. Likewise, choices are presented as guided decisions for the players to consider critically. Lastly, the consequences are reinforcement, recommendations, and suggestions for the outcomes. 
TABLE 3 | Scenario 3.

\begin{tabular}{ll}
\hline Checkpoint 3 & Respond to Digital Offenders \\
\hline
\end{tabular}

Location

Challenge 2nd floor, Makerspace, Main Library

Around 9 p.m., Max is in the maker space editing a video blog that he took in the computer laboratory yesterday. While editing, he found out that he accidentally captured a student who put one computer tablet inside the bag, then walked out of the laboratory. Unfortunately, the face is not clear in the video. Based on the body structure and color of the shirt, Max suspected that it was Alan, his classmate, last semester. If you were Max, what would you do?

\section{Choices}

1. Just delete the video, continue editing the vlog. Remain silent and be neutral.

\section{Consequences}

1. Do not ignore situations like this. You can be a responsible netizen to make our world a better place. As a student, you are expected to be helpful in your little way. One of the responsibilities that come with digital citizenship highlights the need to respond to digital offenders to help solve the offense.

2. Contact the laboratory personnel about what you captured for them to investigate. Email the file to them.

3. Send a private message to Alan and verify from him if it was him in the video.

4. Post the video on your FB with the caption, "Do you know this culprit?"
2. Good Job! You are a responsible social media user. One of the responsibilities of digital citizenship highlights the need to respond to digital offenders that can help the offense. Nevertheless, it does not entail investigating on your own. It merely requires that you report the offender to concerned offices or, if necessary, to the proper legal authorities.

3. Do not message him. As a responsible netizen, be more sensitive. You may be misinterpreted if you confront via instant-messaging. One of the responsibilities of digital citizenship highlights the need to respond to digital offenders that can help the offense. However, it does not entail investigating on your own. Understand your limitations.

4. You are not a responsible social media user. Do not post videos that are "disruptive, threatening, profane, abusive, harassing, embarrassing, tortuous, defamatory, obscene, libelous, or is an invasion of another's privacy." It will not help the situation. It may worsen the situation. After all, you only captured a few seconds of the situation. You did not know the real story.

TABLE 4 | Scenario 4.

\section{Checkpoint 4}

Location

Challenge
Do not tell the world about the upcoming Vacation

3rd floor, Fiction Nook, Main Library

While Max is reading a fiction book, he receives an SMS message from his Dad, informing him that they will have a family tour in Paris. It is going to be the first time for Max to travel internationally. Which of these acts is a good idea for becoming a responsible social media user?

Choices
1. Max tweeted, "so excited! All of us, including my Nanny,
seeing the Eiffel Tower on November 15, 2021. Goodbye
house and see you on Christmas Day."
2. Max posted a captured photo of their airline ticket and
passport, showing his family's personal information.

3. Max conducted research and read some travel tips online, including negative testimonies about the tourist spots. He downloaded it and forwarded it to his parents.

\section{Consequences}

1. It is not wrong to share excitement online. However, do not reveal the details of your upcoming vacation on social media. Do not tell the world that your house is empty. Your home is susceptible to break-ins and damages. You have to wait until you return home before you post and share your travel memories.

2. It is not wrong to share your excitement online. However, posting a picture of your boarding pass might lead to cybercrimes such as identity theft, duplicate credit cards, account numbers were stolen, and even passwords. If you cannot help yourself by posting your ticket, avoid disclosing sensitive information, especially the bar code, by making it blurry from your picture.

3. Good Job! You are a responsible millennial. The internet is a powerful tool to gain information about places, geography, travel tips, etc. Online testimonies, blogs, forums, and groups are among the venues that you can filter relevant information. It is discouraged to shout out to the world that your house will be empty. Likewise, it is also not advisable to post your airline ticket and passport, showing any sensitive information. Posting a picture of your boarding pass or passport might harm you and your family. Let us all be careful about identity theft, duplicate credit cards, account numbers were stolen, and even passwords.
Figure 3 depicts the process of designing challenges, choices, and consequences. The team came up with four checkpoints. These are: (a) familiarizing security and privacy policies, (b) not expressing concerns about others, even if you think you are anonymous, (c) responding to digital offenders, and (d) not telling the world about an upcoming vacation. The Robert B. \& Meta J. Silliman Main Library was chosen as the location of the trail. The library was chosen as the game's path, being the primary resource center of relevant and updated information and research. Four specific locations of the library were chosen with the assistance of the University Librarian. Storyboards were formulated, ensuring the application of cognitive, affective, and psychomotor domains in the intended outcomes. Services of the location of the library were also depicted in the scene. 


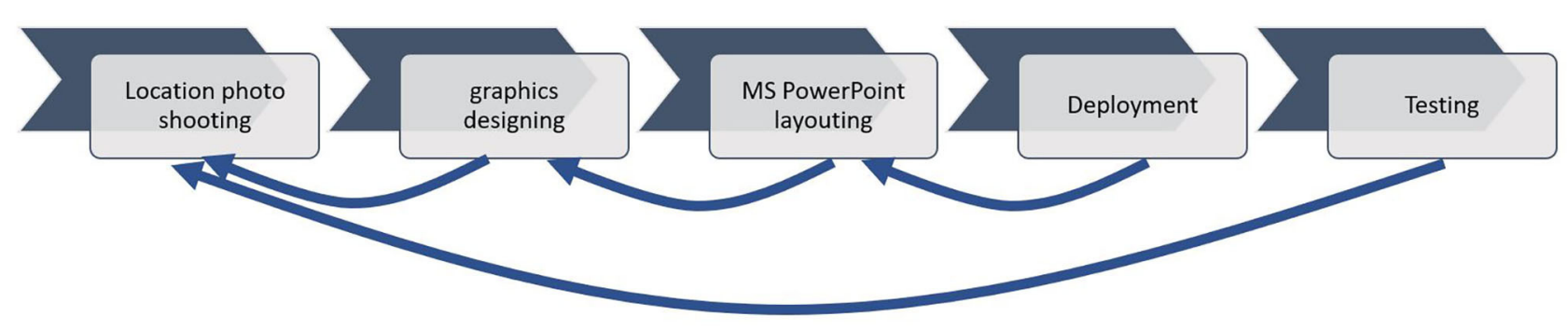

FIGURE 4 | Prototyping
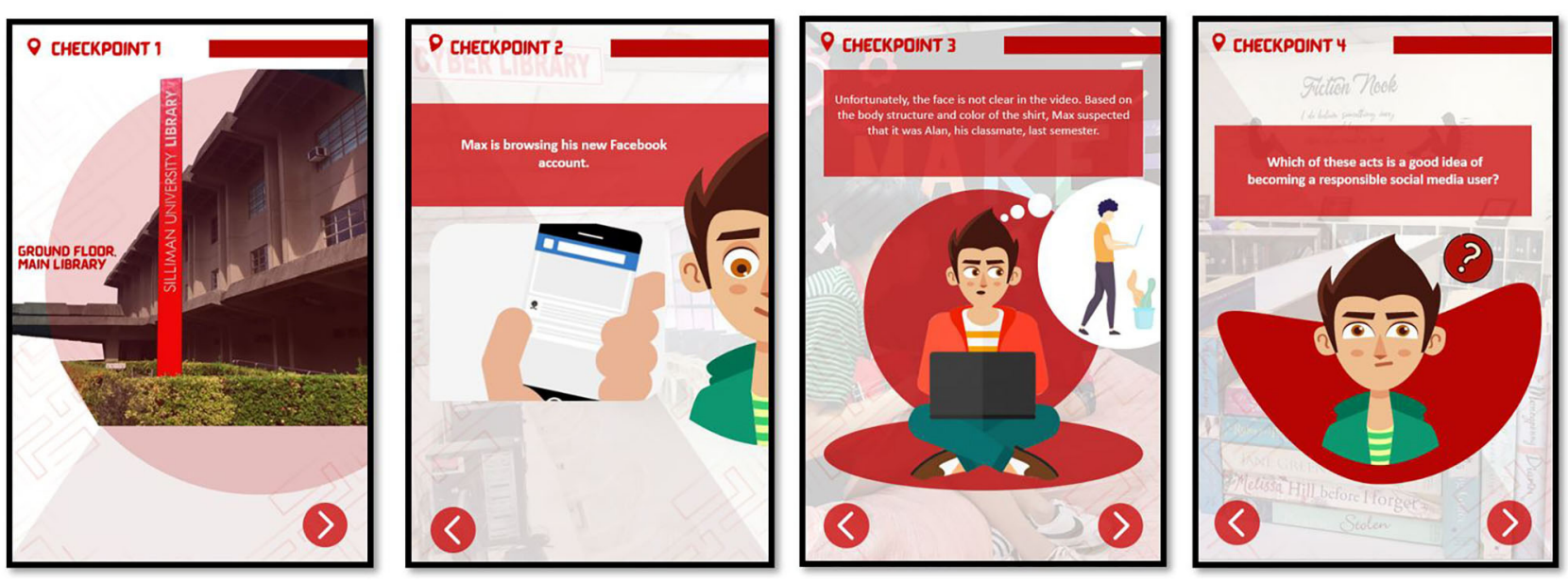

FIGURE 5 | User Interface for every checkpoint.
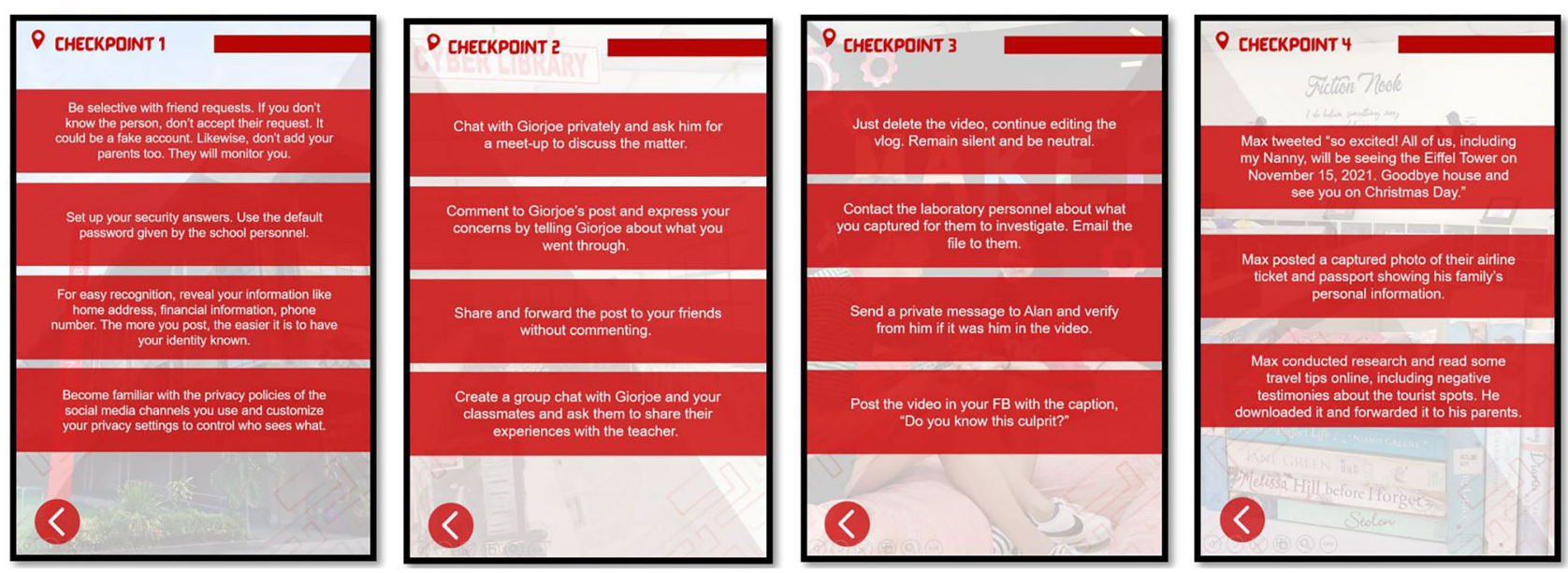

FIGURE 6 | User Interface of the Choices

Formulation of choices was conducted. Choices are guided decisions for the player's consideration. In the responsible use of social media AR Trail app, there are at least three choices in each scenario. Guided decisions are based on related studies, articles, interviews conducted, among others. See Tables 1-4 for the final version of the four scenarios. 

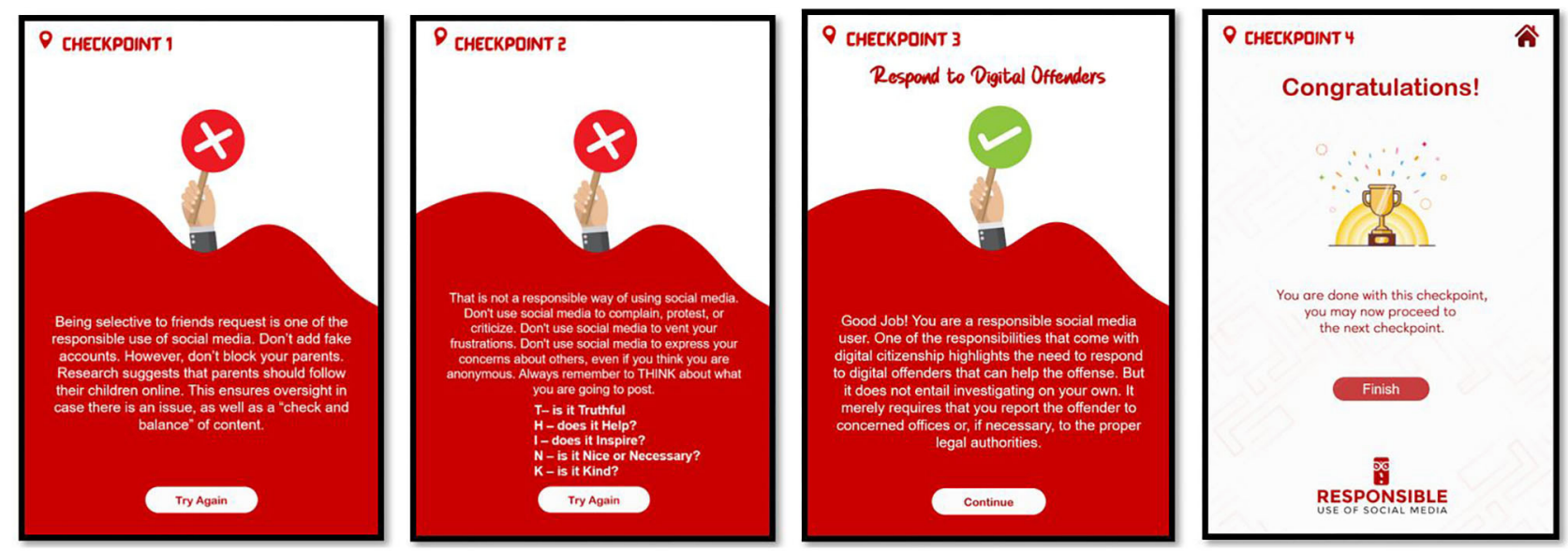

FIGURE 7 | The interface of a wrong and correct choice with the consequence.

\section{The Development Stage}

The team designed the prototype with an emphasis on userinterface and its friendliness, as illustrated in Figure 4. Photo shooting in the identified location was done with consideration of the data privacy of the persons involved in the photos. Other particular considerations during the prototyping development are the presence of the University's branding and userfriendliness. User-friendliness was made sure by following the templates of the mobile AR Trail app, which was developed by the Centre for Holistic Teaching and Learning, Hong Kong Baptist University (CHTL-HKBU). At least five iterations and versions of the design were created before deploying the application to the server. The CHTL-HKBU also hosts the server of the application.

The user interface was designed to be easy for the students and teachers to use and understand. Shown in Figure 5 are sample screenshots showing the user interface for every checkpoint. In contrast, Figure $\mathbf{6}$ are sample screenshots showing the user interface of the choices of every checkpoint. Sample screenshots of the interface of the wrong and correct responses are shown in Figure 7. The following were the considerations in doing the design interface:

1. Youthful and vibrant-when designing, specifically for college students, one must consider how to get the students' attention during an activity. Nowadays, student's participation depends on the content of their activities. If the content is youthful and vibrant, students tend to be very participative compared to a dull and plain-looking activity.

2. Applying Silliman's Identity-applying Silliman's identity to represent the University partaking in the said project. By using the official color of Silliman University, which is red, we were able to design a user interface that reflects the culture of Silliman University, thus, allowing students to spark devotion for their University, leading to more participation in doing the activity.

3. Easy-to-identify-To ensure that the design will impact the students' learnings, the design must be easy-to-identified.
Some of the things are the characters being used and their expressions, the well-laid contents, and the story's flow.

4. Easy-to-use-considering the purpose of the project to provide students learning how to be a responsible social media user, using complicated design will only confuse the students and even the teachers. To contribute to the students' overall learning, we designed a system that is easy to navigate with the content making sure that even first-time users, players, will use the system well.

5. Originality-the essential part of designing the interface is all about one's originality. The more unique it is, the more it will spark curiosity in its users.

QR codes were generated for each checkpoint. These codes were printed and posted in the strategic areas of the identified location. Further, the team also did User-testing. The responsible use of social media AR Trail was also tested by ten students who were taking up the "Empowerment Technologies" subject. An orientation among the testers was provided inside a computer laboratory before the players were immersed in the actual location. Revisions were made based on the comments and suggestions of the testers.

\section{The Implementation Stage}

The responsible use of social media AR Trail was integrated into the subjects "Empowerment Technologies", "Educational Technology," and "Whole Person Education." A 4-day pilot utilization of the app was conducted among seven classes, with 280 students. The students performed the actual trail on four different locations in the library. A short briefing was conducted before the start of the actual game. The Informed Consent that is embedded in the application was also emphasized during the orientation.

\section{The Evaluation Stage}

Integrated into the game is a survey that is aimed to measure the overall player's experience. The questionnaire is composed of 


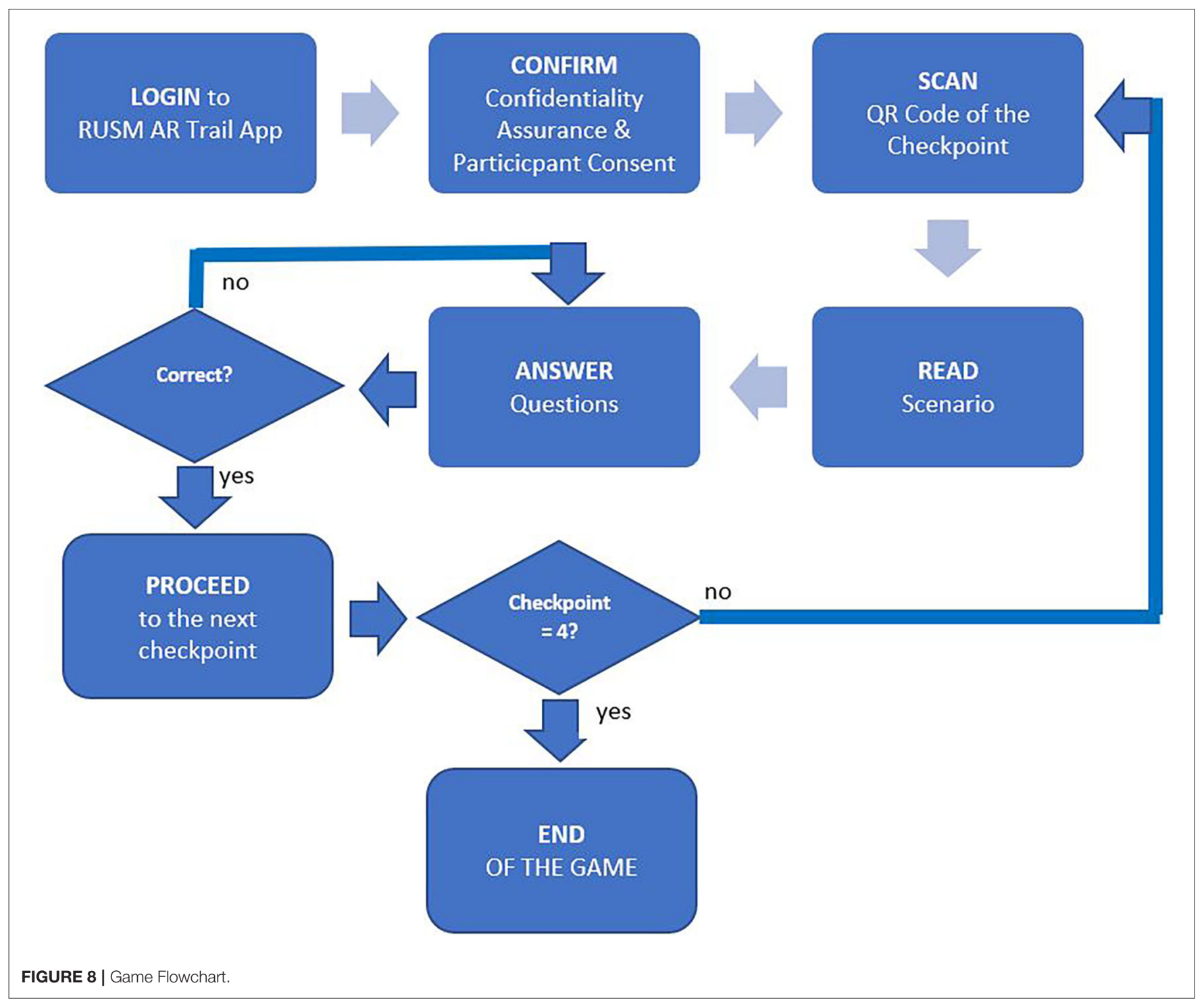

TABLE 5 | RUSM AR trail game mechanics.

\begin{tabular}{|c|c|}
\hline Game mechanics & Description \\
\hline Challenge & At the shortest time, the player must answer the four challenges about the responsible use of social media correctly \\
\hline Reward & Each trail is translated into questions where players need to answer correctly to move on to the next location. \\
\hline Competition & $\begin{array}{l}\text { Several players can play the game at one time. A player who answered correctly at the shortest time will be declared the } \\
\text { winner. }\end{array}$ \\
\hline User engagement & $\begin{array}{l}\text { The game can be played using a Smartphone, either iOS or Android applications. The payer needs to install the game. QR } \\
\text { codes are utilized to interact with the game. The players need to follow the trail. }\end{array}$ \\
\hline
\end{tabular}

eight (8) statements. These are (a) I find this App easy to use, (b) My interaction with this App is clear and understandable., (c) This App makes learning responsible use of social media more interesting., (d) Working with this App is fun., (e) The WiFi connection is stable., (f) I learned a lot from the trail., (g) I would like my teachers to integrate apps like this in my classes., and (h)
It is easy to accomplish the task mentally and physically using this app. Respondent-players were asked to respond using the 5 -point Likert Scales: $5=$ strongly agree, $4=$ agree, $3=$ neutral, 2 $=$ disagree, and $1=$ strongly disagree.

A short processing activity through a focused group discussion was conducted a week after the game's actual use. 


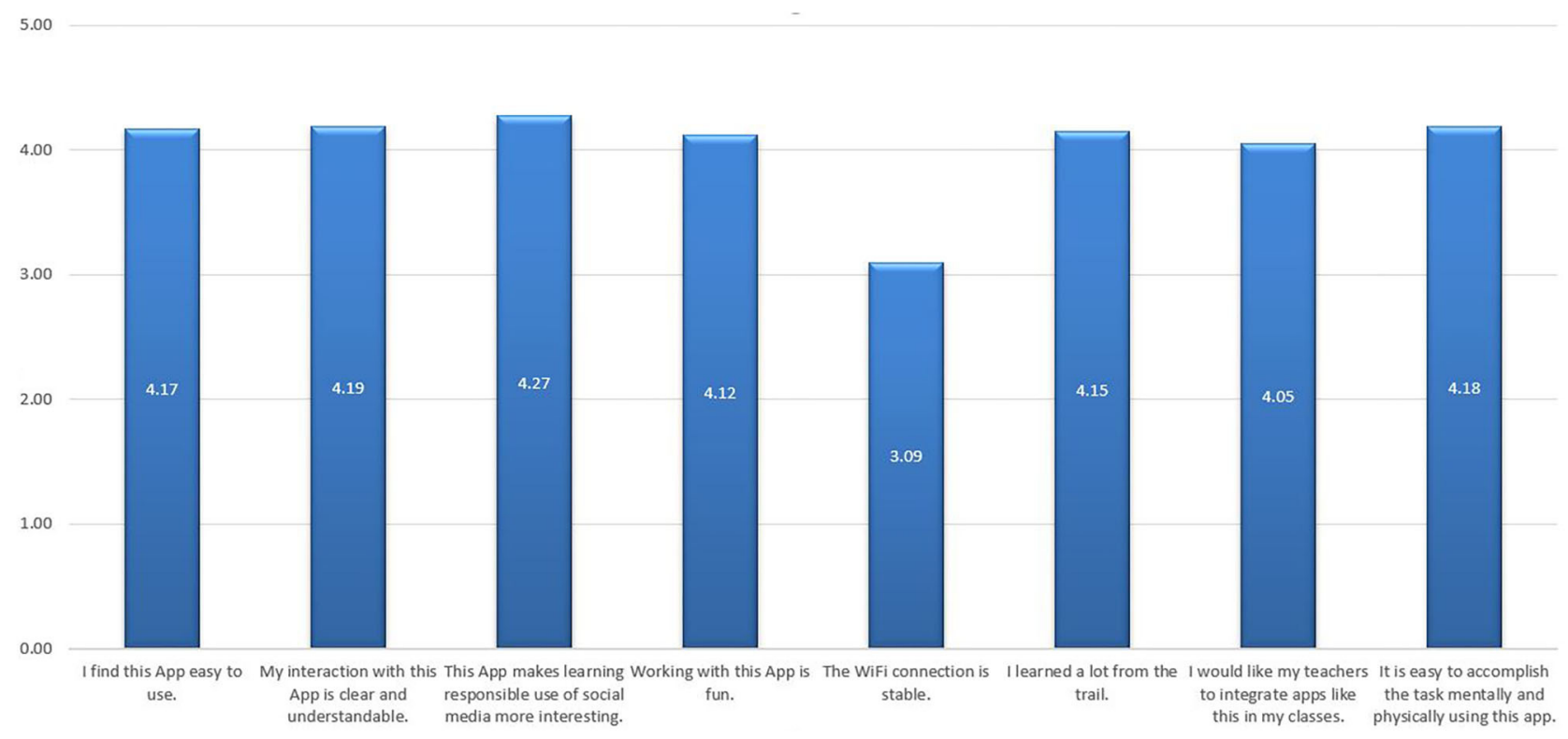

FIGURE 9 | Survey Evaluation.

It was aimed to capture qualitative evaluations that were not captured in the evaluation survey. The processing of the student's learning was conducted in the respective classrooms. A student in every class was asked to recite and share their experiences and lessons learned during the trail. Similarly, the 9 teachers who were part of the project team also evaluated and reflected the entire project implementation.

\section{THE GAME MECHANICS}

The game's goal is to get the correct answer to all the questions about becoming responsible for social media in the shortest time possible. Before the player can start the game, they have to confirm the confidentiality assurance and participant consent. Players need to scan the QR code of each location to view the augmented scenarios of each checkpoint. To follow the trail, the players should get the correct answer per challenge of the checkpoint. Otherwise, the player cannot proceed to the next checkpoint. There are four checkpoints, and each checkpoint is placed in different locations in the University Library. Figure $\mathbf{8}$ is the flowchart of the game.

Four challenges were developed that emphasize (a) familiarity with security and privacy policies, (b) expressing concerns about others, even if you think you are anonymous, (c) responding to digital offenders, (d) telling the world about an upcoming vacation. These challenges were translated into graphics and animations. The animated material was compiled, programmed, and published to a server of the mobile application. The gamified learning trail on responsible use of social media is accessible through QR codes leading to the augmented reality interface. The design was validated and found to be relevant and engaging.
Table 5 is the summary of the description of the responsible use of social media AR Trail game mechanics.

\section{THE GAME EVALUATION RESULTS}

The overall mean of the evaluation is 4.03, described as "agreed." It implies that the game has elements that encourage student participation. It may also mean that the game has engaging factors that allow students to learn (Kapp et al., 2013). As shown in Figure 9, the student-respondents strongly agreed $(\bar{x}=4.27)$ that the app makes learning responsible use of social media more interesting. The respondents agreed that their interaction with the app is clear and understandable $(\bar{x}=4.19)$. The application is easy to accomplish the task mentally and physically $(\bar{x}=4.18)$. The app is easy to use $(\bar{x}=4.17)$ and the students had fun while playing $(\bar{x}=4.12)$. Most importantly, the students agreed $(\bar{x}=$ 4.15) that they learned a lot about the AR trail. The students also agreed $(\bar{x}=4.05)$ to the statement, "I would like my teachers to integrate apps like this in my classes." This result implies that the AR and gamification as teaching strategies in the classroom are perceived positively and accepted. Expectedly, the Wi-Fi connection does not meet the expected stability to efficiently run the game app $(\bar{x}=4.05)$. The result also denotes that the project team successfully integrated well-designed game mechanics and dynamics (Robson et al., 2015). Likewise, the result signifies that the team successfully translated responsible use of social media content and delivery into a game that motivates students to learn (Fuchs et al., 2014).

Further, all seven students who shared during the focusedgroup discussions said they enjoyed a lot the whole experience and suggested continuing this activity in future classes. Moreover, all teachers said that the activity provided a new and innovative 
way of learning and teaching at Silliman University. They said that the activity is responsive to the University's strategic trust in people, programs, and partnerships. The teachers also believed that the activity promoted multicultural knowledge-sharing and transfer. A teacher said

"Being involved in the project made me realize that latest trends in teaching pedagogy that is coupled with technology is really the "in thing" for the kind of learners that we have right now. So, for us teachers to harness our students' 21st century skills, we should also be open-minded to adapt and use the latest trends like augmented reality and gamification in our respective classrooms."

\section{CONCLUSION AND RECOMMENDATION}

A gamified content of the topic "responsible use of social media" was successfully designed and well-developed. The Responsible Use of Social Media-AR Trail offers a highly satisfactory experience among the student-players as well as the teachers. The application comprises features that motivate students to learn in a fun and interactive way. The gamified application offers positive pedagogical benefits among the learners and students.

In general, the study impacted both the students and teachers. The study provided a new and innovative way of learning responsive to the demand of 21 st-century learning. Likewise, it provided an opportunity for the teachers to be immersed in a technology-oriented teaching strategy. The study allowed the teachers to translate a topic into scenarios and challenges for critical thinking.

Designing an instructional augmented reality trail game must be carefully designed. A game application must be able to respond to the intended learning outcomes of the subject. Game designers and developers must possess a certain level of understanding of the content. Prototyping is a critical process to ensure that instructional components and game aspects are intertwined

\section{REFERENCES}

Bell, K. (2018). Game On! Gamification, Gameful Design, and the Rise of the Gamer Educator. Baltimore, MD: Johns Hopkins University Press.

Carmigniani, J., and Furht, B. (2011). "Augmented Reality: an overview," In Handbook of Augmented Reality, ed B. Furht (Boca Raton, FL: Springer Science+Business Media, LLC). doi: 10.1007/978-1-4614-0064-6_1

Cayabyab, M. J. (2020). PhilStar. Available online at: https://www.philstar. com/nation/2020/05/14/2013842/nbi-summons-mocha-fake-news (accessed March 6, 2021).

Chi-Yin Yuen, S., Yaoyuneyong, G., and Johnson, E. (2011). Augmented reality: an overview and five directions for $\mathrm{AR}$ in education. J. Educ. Technol. Dev. Exchange 4, 118-140. doi: 10.18785/jetde.0 401.10

Clement, J. (2020). Number of Social Network Users Worldwide From 2017 to 2025. Available online at: https://www.statista.com/statistics/278414/numberof-worldwide-social-network-users/ (accessed October 15, 2020).

Common Sense Media. (2018). Social Media, Social Life: Teens Reveal Their Experiences. Available online at: https://www.commonsensemedia.org/socialmedia-social-life-infographic (accessed September 28, 2020).

Fuchs, M., Fizek, S., Ruffino, P., and Schrape, N. (2014). Rethinking Gamification. Lüneburg: Meson Press; University of Lüneburg.

GlobalWebIndex. (2019). Social: GlobalWebIndex's Flagship Report on the Latest Trends in Social Media. GlobalWebIndex. Available online at: https://www. cohesively. It is recommended to add more scenarios that will depict situations depicting digital citizenships and whole-person education. Moreover, a thorough study should be conducted to quantify the application's learnings, skills, and achievements.

\section{DATA AVAILABILITY STATEMENT}

The raw data supporting the conclusions of this article will be made available by the authors, without undue reservation.

\section{ETHICS STATEMENT}

The studies involving human participants were reviewed and approved by Centre for Holistic Teaching and Learning, Hong Kong Baptist University. The patients/participants provided their written informed consent to participate in this study.

\section{AUTHOR CONTRIBUTIONS}

All authors listed have made a substantial, direct and intellectual contribution to the work, and approved it for publication.

\section{FUNDING}

This study was funded by United Board for Christian Higher Education in Asia.

\section{ACKNOWLEDGMENTS}

The assistance of Dr. Eva Wong and her team in the Centre for Holistic Teaching and Learning, Hong Kong Baptist University, is much appreciated. Likewise, we also acknowledged the assistance of the Silliman University Library, College of Computer Studies, and Dr. Mariano Lao Innovation, Creation, and Invention Center.

globalwebindex.com/hubfs/Downloads/2019\%20Q1\%20Social\%20Flagship \%20Report.pdf (accessed October 25, 2020).

Gonsenhauser, A. (2017). Five Easy Steps to Analyze Any Problem. Available online at: https://go.forrester.com/blogs/fiveeasystepstoanalyzeanyproblem/\#: $\$ \backslash$ sim \$:text=\%20Key\%20steps\%20to\%20problem\%20analysis\%3A\%20\%201, test $\% 3 \mathrm{~F} \% 20 \mathrm{Here} \% 20$ we\%20state\%20the\%20impact...\%20More\%20 (accessed September 29, 2020).

Gu, J., and Duh, H. B. L. (2011). "Mobile augmented reality game engine." in Handbook of Augmented Reality, ed B. Furht (New York, NY: Springer Science+Business Media, LLC), 99-122. doi: 10.1007/978-1-4614-0064-6_4

Kapp, K. M., Blair, L., and Mesch, R. (2013). The Gamification of Learning and Instruction Fieldbook: Ideas into Practice. San Francisco, CA: John Wiley Sons, Inc.

Krämer, N. C. (2017). "Using new media and technology to foster learning by means of social immersion." in Virtual, Augmented, and Mixed Realities in Education, eds D. Liu, C. Dede, R. Huang, and J. Richards (Singapore: Springer Nature Singapore Pte Ltd.), 55-70.

Kuhlmann, T. (2009). Build branched e-learning scenarios in three simple steps. The Rapid E-Learning Blog. Available online at: https://blogs.articulate.com/ rapid-elearning/build-branched-e-learning-scenarios-in-three-simple-steps/ (accessed September 29, 2020).

Merriam-Webster. (n.d). Merriam-Webster.com Dictionary. Available online at: https://www.merriam-webster.com/dictionary/gamification (accessed October $29,2020)$. 
Profiletree.com. (a). (2020) Types of Augmented Reality - A Quick Read Guide. Available online at: https://profiletree.com/ types-of-augmented-reality/\#:\$ $\$$ sim \$:text=Different\%20Types \%20of\%20Augmented\%20Reality\%201\%20Marker-Based \%20Augmented,Reality.\%20...\%204\%20Superimposition\%20Based\%20Augmented\%20Reality.\%20 (accessed October 29, 2020).

Richter, F. (2018). Teens' social media usage is drastically increasing. Statistica. Available online at: https://www.statista.com/chart/15720/frequency-ofteenagers-social-media-use/ (accessed November 29, 2020).

Robson, K., Plangger, K., Kietzmann, J. H., McCarthy, I., and Pitt, L. (2015). Is it all a game? Understanding the principles of gamification. Bus. Horiz. 58, 411-420. doi: 10.1016/j.bushor.2015.03.006

Royal Society for Public Health. (n.d). (2019) \#StatusofMind. Available online at: https://www.rsph.org.uk/our-work/campaigns/status-of-mind.html (accessed November 29, 2020).

Sheldon, P. (2015). Pavica Sheldon. Lanham, MD: Lexington Books.

Techno Crazed. (2014). 10 Negative Effects Of Social Media On Children And Teenagers. Available online at: http://www.technocrazed.com/top-10negative-effects-of-social-media-on-children-and-teenagers\#:\$ $\$$ sim $\$$ :text= $10 \% 20$ Negative $\% 20$ Effects $\% 20$ Of $\% 20$ Social $\% 20$ Media $\% 20$ On\%20Children,... \%204\%20Identity\%20theft.\%20...\%20More\%20items...\%20 (accessed November 29, 2020).
UNESCO. (2018). Safe, Effective and Responsible Use of
ICT. Available online at: content/safe-effective-and-responsible-use-ict (accessed October 29, 2020).

White, B., King, I., and Tsang, P. (2014). Social Media Tools and Platforms in Learning Environments. Berlin: Springer Berlin.

Wu, H., Wen-Yu Lee, S., Chang, H., and Jyh-Chong, L. (2013). Current status, opportunities and challenges of augmented reality in education. Comput. Educ. 62, 41-49. doi: 10.1016/j.compedu.2012. 10.024

Conflict of Interest: The authors declare that the research was conducted in the absence of any commercial or financial relationships that could be construed as a potential conflict of interest.

Copyright (C) 2021 Marcial, dela Peña, Montemayor and Dy. This is an open-access article distributed under the terms of the Creative Commons Attribution License (CC BY). The use, distribution or reproduction in other forums is permitted, provided the original author(s) and the copyright owner(s) are credited and that the original publication in this journal is cited, in accordance with accepted academic practice. No use, distribution or reproduction is permitted which does not comply with these terms. 